\title{
Reliability Evaluation of Renewable Energy Share in Power Systems
}

\author{
Zeyad A. Haidar, Abdullah M. Al-Shaalan \\ Electrical Engineering Department, King Saud University, Riyadh, Saudi Arabia \\ Email: z.haidar1@yahoo.com,shaalan@ksu.edu.sa
}

How to cite this paper: Haidar, Z.A. and Al-Shaalan, A.M. (2018) Reliability Evaluation of Renewable Energy Share in Power Systems. Journal of Power and Energy Engineering, 6, 40-47.

https://doi.org/10.4236/jpee.2018.69006

Received: August 13, 2018

Accepted: September 18, 2018

Published: September 21, 2018

Copyright ( $) 2018$ by authors and Scientific Research Publishing Inc. This work is licensed under the Creative Commons Attribution International License (CC BY 4.0).

http://creativecommons.org/licenses/by/4.0/

\section{cc) (i) Open Access}

\begin{abstract}
In this research, Renewable Energy (RE) represents the existing power systems with different levels. However, because of the intermittent nature of these sources, it is necessary to analyze systems' reliability with different RE penetration levels. This work presented a simulation method for reliability evaluation of renewable penetrated power systems. Some reliability indices were proposed for the case of power systems with renewable power plants. The adopted approach used the historical data of renewable energy resources, mainly wind and solar to estimate the power that can be generated and compared with the demand to find the power mismatch. Therefore, this approach can be utilized to determine the penetration level that renewable energy can be shared, and it also helps the system operators in deciding the percentage of the generation that RE power plant can provide.
\end{abstract}

\section{Keywords}

Reliability Evaluation, Renewable Energy, Wind Energy, Solar Energy

\section{Introduction}

Integration of renewable energy sources in power system has the advantage of reducing $\mathrm{CO}_{2}$ emission, hence assisting in resolving the global warming problem. It also helps decrease our dependency on fossil fuel in power sectors. Therefore, RE resources are considered a part of the solution to mitigate environmental problems caused by the use of conventional energy resources. In this sense, these resources offer clean energy generation, allowing the electrification of no-connected and remote areas, contribute to decrease dependence on fossil fuels. They also have improved their technologies and reduced costs. However, the capital cost of renewable power plant is very high compared to conventional power plants. But the operation and maintenance cost is cheaper than the one 
for conventional generation and will continue to decline with recent technical development.

Since most of renewable resources are intermittent in nature, it is advantageous to utilize more than one resource when available. Hybridizing of renewable resources improves the power system reliability, efficiency and economy, especially in places with good characteristics of sun and wind.

Integration of wind turbine generator and PV in conventional small isolated power system significantly lowers operating cost by offsetting costly fuel consumed by diesel generators. However, limitations in the energy available from PV system and their intermittent behavior degrade the system reliability. Therefore, cost benefit analysis associated with application of PV is incomplete without corresponding reliability assessment [1].

The reliability of PV systems has been the subject of several research studies going back to at least the 1970's. Early work was focused on component reliability [2] [3]. Current research tends to focus on grid-tied rather than off-grid systems. The research often tries to develop new methods of conceptualizing or calculating reliability, often using probabilistic approaches. A Markov Reward Model was developed in [4] to incorporate reliability into grid-tied PV performance analysis. In [5], the authors proposed a new technique to incorporate reliability into the levelized cost of energy of grid-tied PV systems. The impact of distributed generation DG on the reliability of power system is investigated [6]. They studied optimization of placement of DG to improve the power system reliability using the VCS algorithm.

Methods for calculating the reliability of off-grid systems using the loss of load probability method are implemented in [7] based on probabilistic models. Off-grid systems are also considered in [8], where the authors integrate reliability aspects into the design of such systems. Other existing research considers the reliability of hybrid systems [9] and multi-grids [10] using various probabilistic techniques.

This paper presents a method to evaluate the reliability of renewable power systems. Three scenarios were used: a power system with wind energy, solar energy and hybrid system. Although the actual case includes a variable load, the load was assumed to be constant for the sake of simplicity. The historical data of wind speed and solar radiation for Riyadh were used to calculate the generation power from wind and/or solar energy at each minute for one month. Since solar PV panels' output changes with their operating temperature, the ambient temperature was also included in the study. The aim of this study is to present or propose a method to classify the availability of renewable energy based on the historical data of the renewable resources, like wind speed and solar radiation. The availability of renewable resources can cover or feed the whole load, or it can share a percentage of the total load and the remaining is fed or supplied using conventional power plants. Therefore, this paper introduces new indices for renewable energy reliability assessment that can be used in power systems planning and operation. These indices are 25\% energy index, 50\% energy index, $75 \%$ 
energy index and 100\% energy index. Each index gives the probability that the expected available renewable resources will cover $25 \%, 50 \%, 75 \%$ and $100 \%$ of the energy demand respectively during the study time.

\section{Mathematical Modeling}

The proposed indices in this study are calculated using the following equation:

$$
N \% \text { index }=P(r e>N \%)
$$

where $r e$ is the available renewable energy, $P(r e>N \%)$ the probability that re is $>$ than $N \%$ of the load, $N$ represents $25,50,75$ or 100 or any percent.

Therefore, 25\% index gives the percent of time (over the period of study) at which the expected renewable energy is less than $25 \%$ of load, $50 \%$ index gives the percent of time at which the expected renewable energy is less than $50 \%$ of load so on.

This index attempts to answer the question: how many days (or hours) do we expect that renewable energy resources will supply $N \%$ of the load during a specified period? The benefit of using this index is to determine the adequacy of renewable resources to supply a specified portion of the load, and consequently; the conventional generation that is required to supply the remaining part of the total load. The accuracy of this method depends on the number of weather data that is included in the calculation and can be improved further, if data from forecasting models are inserted in the calculation of the renewable resources.

The wind power generated by wind turbines is calculated using the following equation [11]:

$$
P_{w}=0.5 N_{t} A C_{p} w^{3} \eta
$$

where $\rho$ is the air density in $\mathrm{kg} / \mathrm{m}^{3}, \mathrm{~A}$ is the rotor swept area in $\mathrm{m}^{2}, C_{p}$ is the turbine coefficient of performance, $\mathrm{w}$ is the wind speed at hub position $\mathrm{m} / \mathrm{s}, N_{t}$ is the number of turbines and $\eta$ is the net efficiency. The theatrical value of $C_{p}$ is $59.3 \%$.

The solar energy can be calculated using the following equation [12]:

$$
P_{S}=I A_{p} N_{p} \eta
$$

where $I$ is the solar radiation in $\mathrm{w} / \mathrm{m}^{2}, A_{p}$ is the panel area, $N_{p}$ is the number of panels, and $\eta$ is the panel efficiency.

The simulation was carried out using the following steps:

1) For each $i \in n$, calculate the load and available ER (based on historical data of solar radiation and wind speed), where $i$ is the time step (minutes or hours) and $\mathrm{n}$ is the total time.

2) Compute

$\mathrm{REL}=\frac{\mathrm{RE}}{\mathrm{load}}$ for each $i$, where REL is the level of RE w.r.t. load.

3) Classify the results of step (2) into groups based on level of RE penetration preset by the utility. 


\section{Results and Discussions}

\subsection{Solar Energy}

The number of PVs used in this study is 2000 panels. It is assumed that there are two solar PV plants at different locations and hence different solar radiations. Each location has 1000 panels of $250 \mathrm{~W}_{\mathrm{p}}$.

Figure 1 shows the solar PV energy that is produced during the month of study. The load power is $100 \mathrm{MW}$ and is shown in the figure as horizontal line. The output power of PV panels is less than the load at some minutes and more than the load at others. However, the output power is not similar for all days. In some days the output is fluctuating, and this is indicated by the black areas in the Figure 1 like minute 250,000 ( $17^{\text {th }}$ of the month). The peak of the solar power is not the same each day due to change in the solar radiation and ambient temperature.

Figure 2 shows the values of the proposed indices for solar energy alone. It shows that the availability of solar energy to supply $25 \%$ of the demand during the month is 0.4786 . Therefore, we can expect solar PV power (with 2000 panels) to supply $25 \%$ of the load over a period equals approximately $50 \%$ of the month (15 days). Consequently, conventional energy will supply the remaining (75\% of the load) during these days and the whole load on the others 15 days. However,

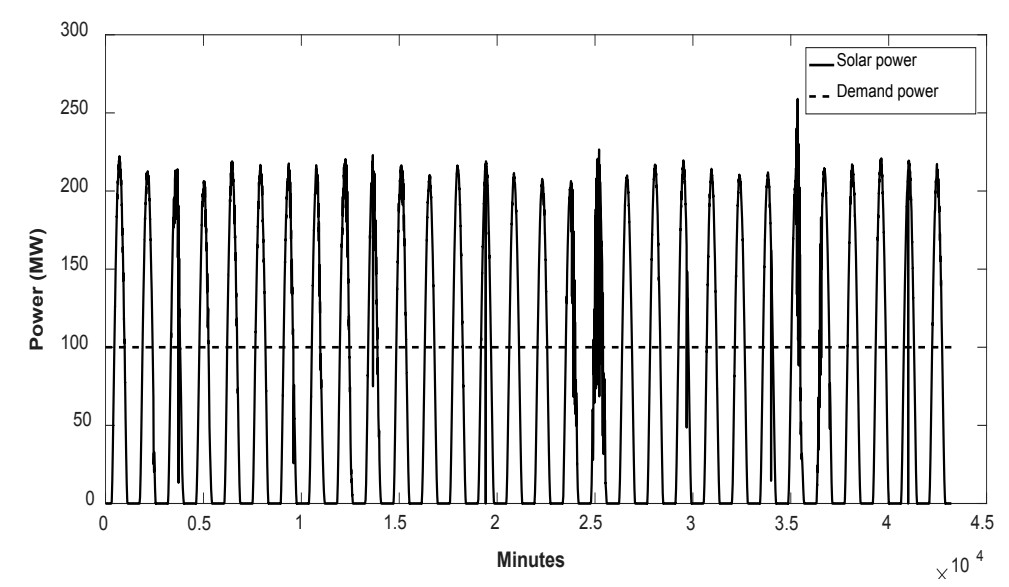

Figure 1. The PV panels' energy produced during the month minutes.

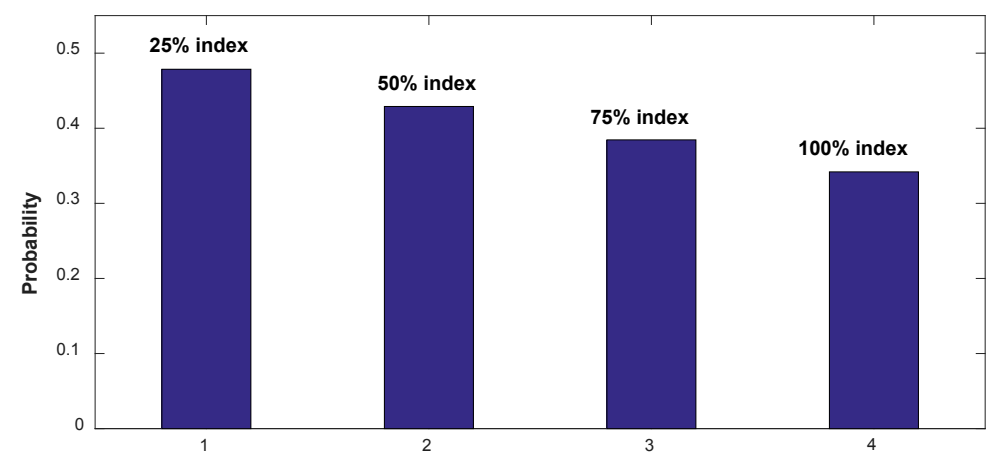

Figure 2. The probability indices of solar energy alone. 
if the number of PV panels is increased, the percentage of the load that can be supplied by the solar will definitely increases. The $50 \%$ index value is 0.43 which is lower than $25 \%$ index. This means that the solar energy can supply $50 \%$ of the energy demand has a percentage of 0.43 during the month. Figure 2 shows that solar energy can supply the whole load during 0.34 of the month i.e., during 10 days.

\subsection{Wind Energy}

Since wind energy is of intermittent and fluctuating nature compared with the solar energy, therefore, it is hard to predict and anticipate.

Figure 3 shows the wind energy produced from wind turbines alone (no solar PV panels). It shows the highly intermittent nature of wind energy. If we compare Figure 3 with Figure 1, we can see that solar energy is more stable and consistent. From Figure 3, the wind energy can supply the whole load for only short periods between the $7^{\text {th }}$ and $10^{\text {th }}$ days. In most of the month time the wind energy is lower than the energy demand.

Figure 4 shows the values of the proposed indices for wind energy alone. It shows that the probability that wind energy will supply $25 \%$ of the demand during the month is 0.16 . Therefore, we can rely on wind power (with 2000 wind turbines) to supply $25 \%$ of the load approximately $16 \%$ of the month (4.8 days) which is very small compared to that of solar energy. Therefore, it can be concluded that wind energy in this case is less reliable than solar energy. The values

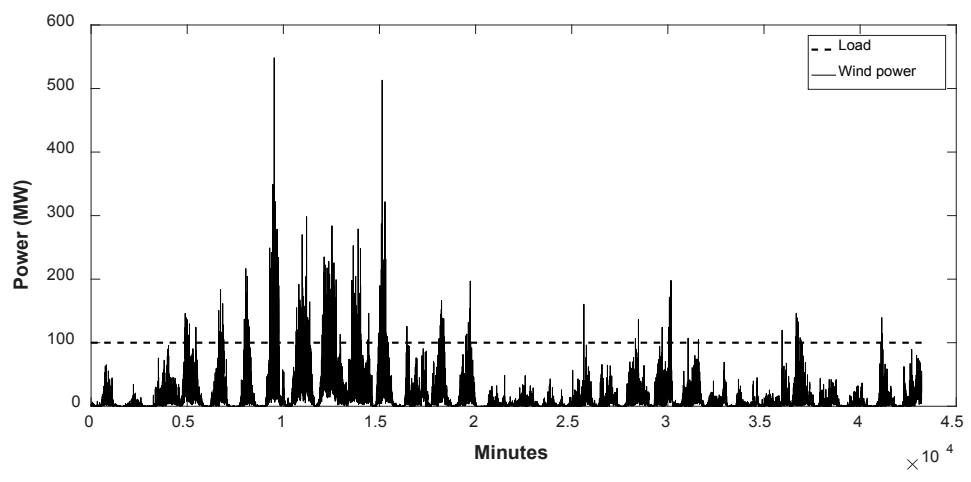

Figure 3. The wind energy produced during the month minutes.

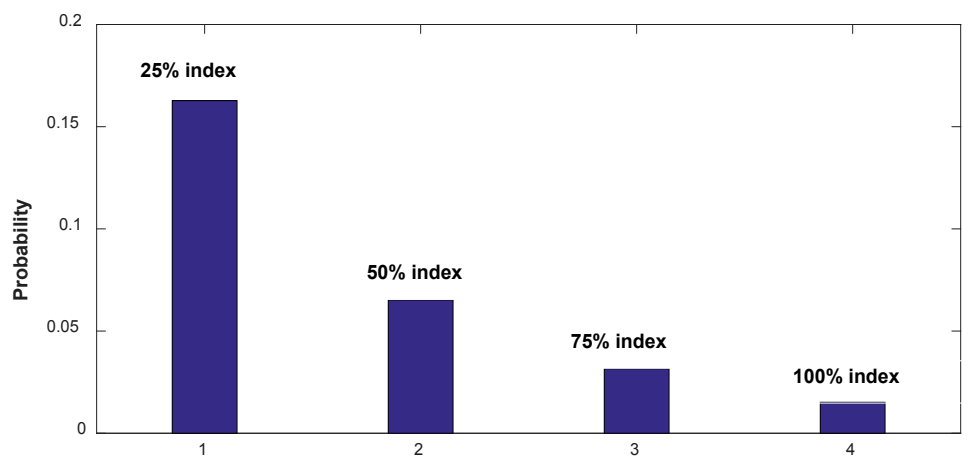

Figure 4. The probability indices of wind energy alone. 
of $50 \%$ index, $75 \%$ index and $100 \%$ index is $0.065,0.031$ and 0.015 respectively.

\subsection{Hybrid System (Solar-Wind Energy)}

Figure 5 shows the case of hybrid generation. Both wind and solar are utilized to supply the load. It can be seen that the wind energy fills some gaps left by the solar energy in the area under the load line. This means more load will be supplied and the reliability will enhances.

Figure 6 shows the reliability (availability) indices values of the hybrid system. The value of the $25 \%$ index is 0.55 which is larger than that of solar and wind alone. Therefore, $25 \%$ of the demand energy can be supplied by this renewable system during 0.55 of the month (16.5 days). The values of the $50 \%, 75 \%$ and $100 \%$ indices are $0.46,0.410 .37$ respectively. That means this systems can supply $50 \%, 75 \%$ and $100 \%$ of the load during $0.46,0.41$ and 0.37 of the month (13.8, 12.3 and 11.1 days).

It can be concluded that hybridizing different renewable resources improves the system reliability and energy availability.

Figure 7 shows comparison between the three cases, where $S$ denotes the solar energy, $\mathrm{W}$ denotes the wind energy and $\mathrm{H}$ the hybrid energy. It highlights the fact that reliability of renewable power systems can be improved by using more than one type of energy resources.

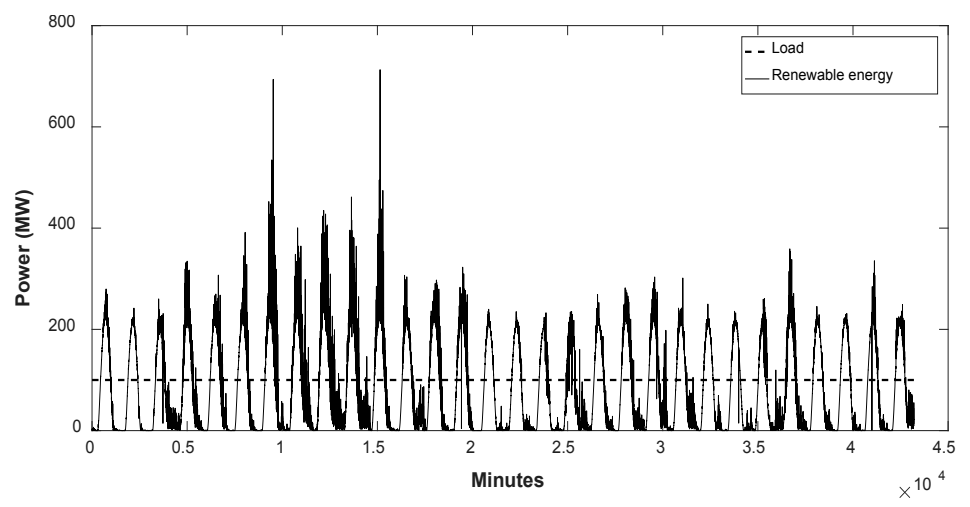

Figure 5. The renewable hybrid energy produced during the month minutes.

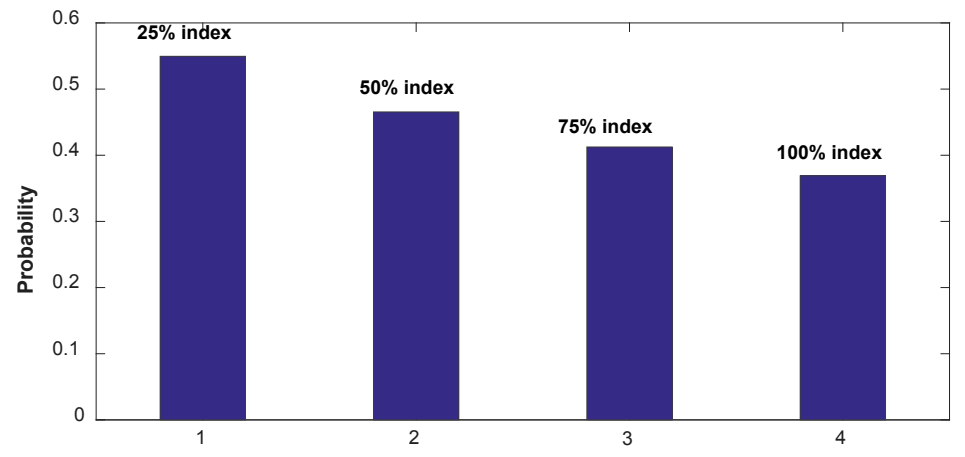

Figure 6. The probability indices of the hybrid system. 


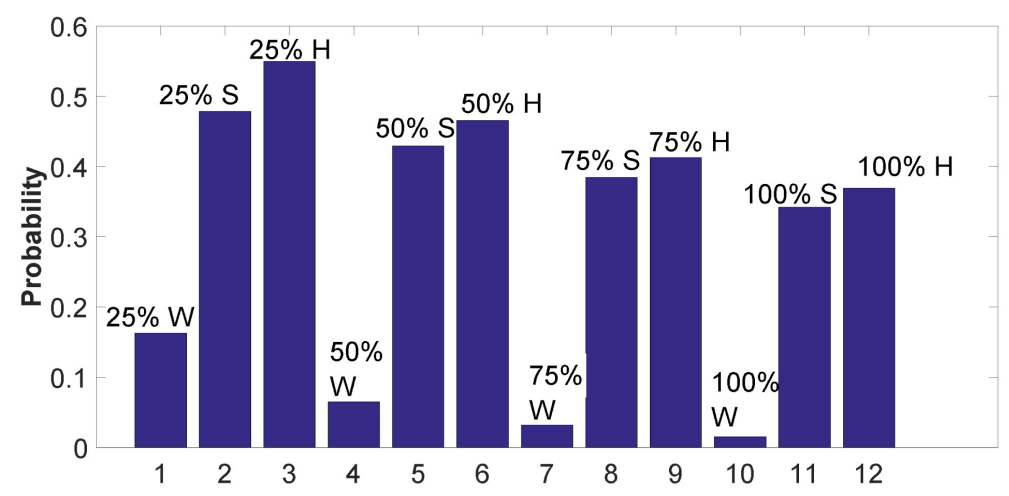

Figure 7. Comparison the three cases, solar alone, wind alone and hybrid systems.

\section{Conclusion}

This work presented a simulation method based on a statistical method to evaluate the availability of renewable energy power that can be quantified in supplying the load in advance over a period reliably and adequately. It was shown that, hybridizing different renewable resources (i.e. wind and solar) will improve the system's reliability and dependability. The benefit of the approach adopted and used in this work is that it can utilize historical data rather than forecasted ones.

\section{Conflicts of Interest}

The authors declare no conflicts of interest regarding the publication of this paper.

\section{References}

[1] Billinton, R. and Karki, R. (2001) Maintaining Supply Reliability of Small Isolated Power Systems Using Renewable Energy. IEE Proceedings-Generation, Transmission and Distribution, 148, 530-534. https://doi.org/10.1049/ip-gtd:20010562

[2] Stember, L., Huss, W. and Bridgman, M. (1982) A Methodology for Photovoltaic System Reliability \& Economic Analysis. IEEE Transactions on Reliability, 31, 296-303. https://doi.org/10.1109/TR.1982.5221344

[3] Longrigg, P. (1978) System Design and Economic Analysis of a Solar Photovoltiac Power Supply. International Telephone Energy Conference, INTELEC78, Washington DC, 114-120.

[4] Dhople, S.V. and Dominguez-Garcia, A.D. (2012) Estimation of Photovoltaic System Reliability and Performance Metrics. IEEE Transactions on Power Systems, 27, 554-563. https://doi.org/10.1109/TPWRS.2011.2165088

[5] Shimura, S., Herrero, R., Zuffo, M.K. and Grimoni, J.A.B. (2016) Production Costs Estimation in Photovoltaic Power Plants Using Reliability. Solar Energy, 133, 294-304. https://doi.org/10.1016/j.solener.2016.03.070

[6] Hosseini, S.J.A.-D., Moradian, M., Shahinzadeh, H. and Ahmadi, S. (2018) Optimal Placement of Distributed Generators with Regard to Reliability Assessment Using Virus Colony Search Algorithm. International Journal of Renewable Energy Research (IJRER), 8, 714-723. 
[7] Abouzahr, I. and Ramakumar, R. (1991) Loss of Power Supply Probability of Stand-Alone Photovoltaic Systems: A Closed Form Solution Approach. IEEE Transactions on Energy Conversion, 6, 1-11. https://doi.org/10.1109/60.73783

[8] Maghraby, H., Shwehdi, M. and Al-Bassam, G.K. (2002) Probabilistic Assessment of photovoltaic (PV) Generation Systems. IEEE Transactions on Power Systems, 17, 205-208. https://doi.org/10.1109/59.982215

[9] Paliwal, P., Patidar, N. and Nema, R. (2014) A Novel Method for Reliability Assessment of Autonomous PV-Wind-Storage System Using Probabilistic Storage Model. International Journal of Electrical Power \& Energy Systems, 55, 692-703. https://doi.org/10.1016/j.ijepes.2013.10.010

[10] Nikmehr, N. and Ravadanegh, S.N. (2016) Reliability Evaluation of Multi-Microgrids Considering Optimal Operation of Small Scale Energy Zones under Load-Generation Uncertainties. International Journal of Electrical Power \& Energy Systems, 78, 80-87. https://doi.org/10.1016/j.ijepes.2015.11.094

[11] Wagner, F. (2014) Renewable in Future Power Systems. Springer, Essen. https://doi.org/10.1007/978-3-319-05780-4

[12] Jarass, L., Obermair, G.M. and Voigt, W. (2009) Windenergie: Zuverlässige Integration in die Energieversorgung. Springer-Verlag, Berlin.

https://doi.org/10.1007/978-3-540-85253-7 